\title{
Food for Thought ... Why No New In Vitro Tests Will Be Done for REACH by Registrants
}

\author{
Costanza Rovida \\ CAAT-EU, University of Konstanz, Germany
}

REACH is the new European Regulation for the assessment of both toxicological and eco-toxicological risks related to chemicals. It is the most challenging system for chemical safety ever implemented worldwide. The basis for the development of this important regulation was the increasing awareness that thousands of chemicals commonly circulate in the European Union in spite of little knowledge about their (eco)toxicological properties (White Paper, 2001). The increasing incidence of allergic reactions, some tumours, fertility impairment and other diseases contributed to rising concern about the role of chemicals in our daily lives (European Risk Observatory Report, 2009).

According to REACH, all substances that are marketed in the European Union at more than one tonne per year need to be registered by presenting an extensive dossier to the European Chemical Agency (ECHA) located in Helsinki. The extent of this dossier depends on the tonnage band of the manufactured/ imported substances, being very demanding for chemicals circulating above $1000 \mathrm{t} /$ year and less so for thresholds of 100, 10 and $1 \mathrm{t} /$ year. Tables $1 \mathrm{a}-\mathrm{c}$ summarise all data that need to be submitted according to the different Annexes of REACH.

REACH requirements are not limited to a general characterisation of the physico-chemical and (eco)toxicological properties. The dossier must include information about the whole lifecycle of the substance and should be completed with a detailed description about how the chemical is handled, how it is used, how it is disposed of, which are the risk management measures that are implemented and so on.

For all chemicals that are distributed in quantities above 10 t/year, the dossier must include a more extensive Chemical Safety Assessment (CSA) and in case the chemical is classified, the CSA must comprehend a very detailed exposure scenario for workers, consumers and the environment. The delivery of the CSA is part of the Chemical Safety Report (CSR), which is attached to the submission file.

The complexity of the registration dossier needs many different professional skills, ranging from chemistry, toxicology, analytical skills, occupational safety and health, and so on. But these are not the only difficulties. REACH introduces the rule of "one substance, one registration", forcing all parties who are interested in the registration of a given substance to join what is called a SIEF (Substance Information Exchange Forum). The dimensions of a SIEF range from 2-4 companies up to several hundred, typically located in different EU countries. The participants of a SIEF are de facto competitors and day-to-day relationships in the SIEF are generally very difficult, as the participants must agree on a common CSA and share registration costs. This is the level on which lawyers and accountants start working. Each SIEF has a lead registrant, who does most of the job, generally helped by a consultant company, which can take care of different aspects of the registration process.

For the preparation of these complex and multifaceted dossiers, ECHA developed and distributed for free a very comprehensive software-tool, which is called IUCLID 5.2. The starting window of IUCLID 5.2 is shown in Figure 1. The use of this software is complex and probably very few people in Europe have had the opportunity to learn intensively how to deal with it.

\begin{tabular}{|c|c|c|c|c|c|}
\hline \multicolumn{2}{|c|}{ 7. Physicochemical Properties } & $\frac{3}{1}$ & $\mid \begin{array}{l}3 \\
\vdots \\
0 \\
1\end{array}$ & $\begin{array}{l}3 \\
8 \\
0 \\
1\end{array}$ & $\begin{array}{l}3 \\
8 \\
8 \\
0 \\
1\end{array}$ \\
\hline 7,1 & State of the substance & $x$ & & & \\
\hline 7,2 & Melting/freezing point & $x$ & & & \\
\hline 7,3 & Boiling point & $x$ & & & \\
\hline 7,4 & Relative density & $x$ & & & \\
\hline 7,5 & Vapour pressure & $\mathrm{x}$ & & & \\
\hline 7,6 & Surface tension & $x$ & & & \\
\hline 7,7 & Water solubility & $\mathrm{x}$ & & & \\
\hline 7,8 & Partition coefficient octanol/water & $x$ & & & \\
\hline 7,9 & Flash point & $x$ & & & \\
\hline 7,10 & Flammability & $x$ & & & \\
\hline 7,11 & Explosive properties & $x$ & & & \\
\hline 7,12 & Self-ignition temperature & $x$ & & & \\
\hline 7,13 & Oxidising properties & $x$ & & & \\
\hline 7,14 & Granulometry & $x$ & & & \\
\hline 7,15 & Stability in organic solvents & & & $x$ & \\
\hline 7,16 & Dissociation constant & & & $\mathrm{x}$ & \\
\hline 7,17 & Viscosity & & & $\mathrm{x}$ & \\
\hline
\end{tabular}

Tab. 1a: REACH requests for testing: physicochemical properties 
The intricacy of the whole procedure is definitely very high, as evident by the number of guidelines that have been published by ECHA (downloadable from http://guidance.echa.europa.eu). Every month, two or three new guidelines are distributed, demonstrating that the preparation of a dossier is still far from being a well-established process and there are many areas of uncertainty and discussion.

Compared to previous legislation, $\mathrm{REACH}$ asks for a precise definition of more (eco)toxicological endpoints. As a consequence, many new tests, mostly in vivo, need to be performed. The high cost in terms of animal number has been a matter of concern since the very beginning (Pedersen et al., 2003; van der Jagt et al., 2004). Our more recent estimations (Hartung and Rovida, 2009) claim that the total number of animals can be up to 54.4 million if growth of the EU and its chemical industry is considered and the current test guidelines are strictly followed. One way to reduce this number could obviously be the use of in vitro instead of in vivo methods. Is this a realistic possibility?

\begin{tabular}{|c|c|c|c|c|c|}
\hline \multicolumn{2}{|c|}{ 8. Toxicological information } & \multirow{2}{*}{$\begin{array}{l}3 \\
\mathbf{3} \\
\mathrm{x}\end{array}$} & \multirow{2}{*}{$\begin{array}{l}3 \\
ㅇ \\
1 \\
x\end{array}$} & \multirow{2}{*}{$\begin{array}{l}3 \\
\vdots \\
8 \\
1 \\
1 \\
x\end{array}$} & \multirow{2}{*}{$\begin{array}{l}3 \\
8 \\
8 \\
\\
1 \\
x\end{array}$} \\
\hline 8,1 & Skin irritation/corrosion (in vitro) & & & & \\
\hline 8.1 .1 & In vivo skin irritation & & $x$ & $x$ & $x$ \\
\hline 8,2 & Eye irritation (in vitro) & $x$ & $\mathrm{x}$ & $x$ & $x$ \\
\hline 8.2 .1 & In vivo eye irritation & & $\mathrm{x}$ & $\mathrm{x}$ & $x$ \\
\hline 8,3 & Skin sensitisation & $\mathrm{x}$ & $\mathrm{x}$ & $\mathrm{x}$ & $\mathrm{x}$ \\
\hline 8,4 & Mutagenicity & $\mathrm{x}$ & $\mathrm{x}$ & $x$ & $x$ \\
\hline 8.4 .1 & In vitro gene mutagen study in bacteria & $x$ & $x$ & $x$ & $x$ \\
\hline 8.4 .2 & In vitro cytogenicity study & & $x$ & $x$ & $x$ \\
\hline \multirow[t]{2}{*}{8.4 .3} & In vitro gene mutation study & & $x$ & $x$ & $x$ \\
\hline & Further Mutagenicity & & & $x$ & $x$ \\
\hline 8,5 & Acute toxicity & $x$ & $x$ & $x$ & $x$ \\
\hline 8.5 .1 & Acute toxicity (oral route) & $x$ & $x$ & $x$ & $x$ \\
\hline 8.5 .2 & Acute toxicity (inhalation) & & $x$ & $x$ & $x$ \\
\hline 8.5 .3 & Acute toxicity (dermal route) & & $x$ & $x$ & $x$ \\
\hline 8.6. & Repeated dose toxicity & & & & $x$ \\
\hline 8.6.1 & Short term repeated dose toxicity & & $x$ & $x$ & $x$ \\
\hline 8.6 .2 & Sub-chronic toxicity study & & & $x$ & $x$ \\
\hline 8.6 .3 & Long term repeated toxicity study & & & & $x$ \\
\hline 8,7 & Reproductive toxicity & & & & $x$ \\
\hline 8.7.1 & One species screening & & $x$ & $x$ & $x$ \\
\hline 8.7 .2 & Developmental toxicity study & & & $x$ & $x$ \\
\hline 8.7.3 & Two-generation reproductive toxicity study & & & $x$ & $x$ \\
\hline 8,8 & Toxicokinetics & & & & $x$ \\
\hline 8.8 .1 & Toxicokinetics (available information) & & $x$ & $x$ & $x$ \\
\hline 8.9 .1 & Carcinogenicity study & & & & $x$ \\
\hline
\end{tabular}

Tab. 1b: REACH requests for testing: toxicological information

\section{The intentions of REACH}

REACH regulation states in its very first article:

"Article 1 The purpose of this Regulation is to ensure a high level of protection of human health and the environment, in-

\begin{tabular}{|c|c|c|c|c|c|}
\hline \multicolumn{2}{|c|}{ 9. Ecotoxicological Information } & $\frac{3}{1}$ & $\frac{3}{3}$ & $\begin{array}{l}3 \\
8 \\
8 \\
0 \\
1\end{array}$ & $\begin{array}{l}3 \\
8 \\
8 \\
\\
\\
1\end{array}$ \\
\hline 9,1 & Aquatic toxicity & & & & \\
\hline 9.1 .1 & $\begin{array}{l}\text { Short term toxicity testing on } \\
\text { invertebrates (Daphnia) }\end{array}$ & $\mathrm{x}$ & $x$ & $x$ & $x$ \\
\hline 9.1 .2 & Growth inhibition study aquatic plants & $\mathrm{x}$ & $x$ & $x$ & $\mathrm{x}$ \\
\hline 9.1 .3 & Short term toxicity test on fish & & $x$ & $\mathrm{x}$ & $x$ \\
\hline 9.1 .4 & $\begin{array}{l}\text { Activated sludge respiration } \\
\text { inhibition testing }\end{array}$ & & $x$ & $\mathrm{x}$ & $x$ \\
\hline 9.1 .5 & $\begin{array}{l}\text { Long term toxicity testing on } \\
\text { invertebrates (Daphnia) }\end{array}$ & & & $x$ & $x$ \\
\hline 9.1 .6 & Long term toxicity test on fish & & & $\mathrm{x}$ & $\mathrm{x}$ \\
\hline 9.1 .6 .2 & Fish early life stage (FELS) toxicity test & & & $\mathrm{x}$ & $\mathrm{x}$ \\
\hline 9.1 .6 .2 & $\begin{array}{l}\text { Fish short term toxicity test on embryo } \\
\text { and sac-fry stage }\end{array}$ & & & $x$ & $x$ \\
\hline 9.1.6.3 & Fish, juvenile growth test & & & $\mathrm{x}$ & $x$ \\
\hline 9,2 & Degradation & & & & \\
\hline 9.2 .1 & Biotic & $\mathrm{x}$ & $x$ & $\mathrm{x}$ & $\mathrm{x}$ \\
\hline 9.2 .1 & Further Biotic & & & & $x$ \\
\hline 9.2 .1 .1 & Ready biodegradability & & $x$ & $\mathrm{x}$ & $x$ \\
\hline 9.2 .1 .2 & $\begin{array}{l}\text { Simulation testing on ultimate } \\
\text { degradation in surface water }\end{array}$ & & & $x$ & $x$ \\
\hline 9.2 .1 .3 & Soil simulation testing & & & $x$ & $x$ \\
\hline 9.2 .1 .4 & Sediment simulation testing & & & $\mathrm{x}$ & $x$ \\
\hline 9.2 .2 & Abiotic & & $x$ & $\mathrm{x}$ & $\mathrm{x}$ \\
\hline 9.2 .2 .1 & Hydrolysis as a function of $\mathrm{pH}$ & & $x$ & $\mathrm{x}$ & $\mathrm{x}$ \\
\hline 9,3 & Fate and behaviour in the environment & & & & \\
\hline 9.3 .1 & Adsorption/Desorption screening & & $x$ & $\mathrm{x}$ & $\mathrm{x}$ \\
\hline 9.3 .2 & Bioaccumulation in aquatic species (fish) & & & $\mathrm{x}$ & $\mathrm{x}$ \\
\hline 9.3 .3 & $\begin{array}{l}\text { Further information on } \\
\text { adsorption/desorption }\end{array}$ & & & $\mathrm{x}$ & $x$ \\
\hline 9.3 .4 & $\begin{array}{l}\text { Further information on the } \\
\text { environmental fate and behaviour }\end{array}$ & & & & $x$ \\
\hline 9,4 & Effects on terrestrial organisms & & & & \\
\hline 9.4 .1 & Short term toxicity to invertebrates & & & $\mathrm{x}$ & $\mathrm{x}$ \\
\hline 9.4 .2 & Effects on soil microorganisms & & & $\mathrm{x}$ & $\mathrm{x}$ \\
\hline 9.4 .3 & Short term toxicity to plants & & & $x$ & $\mathrm{x}$ \\
\hline 9.4 .4 & Long term toxicity to invertebrates & & & & $\mathrm{x}$ \\
\hline 9.4 .6 & Long term toxicity to plants & & & & $\mathrm{x}$ \\
\hline 9.5 .1 & Long test toxicity to sediment organisms & & & & $\mathrm{x}$ \\
\hline 9.6 .1 & Long term or reproductive toxicity to birds & & & & $x$ \\
\hline
\end{tabular}

Tab. 1c: REACH requests for testing: Ecotoxicological information 
cluding the promotion of alternative methods for assessment of hazards of substances, as well as the free circulation of substances on the internal market while enhancing competitiveness and innovation." (Emphasis added)

The willingness to avoid animal tests is confirmed later in Annex XI, further amended in EU Regulation 134/2009, by:

- Accepting data from non-validated alternative methods, proving the scientific validity

- Implementing the weight of evidence tool for a maximum exploitation of any existing data

- Implementing both grouping and read across to minimise the number of new tests
The legislators' intentions were clear. In fact, REACH is revolutionary, being the first act that officially accepts data from non validated methods and formally fosters approaches such as weight of evidence and Integrated Testing Strategies (ITS). It is important to specify the difference between the two. The former is based on the evaluation of existing data, which may derive from very old studies, non-GLP results or from non official guideline studies. The principle is that all of these data can be "weighed" and combined together for the evaluation of a specific toxicological property. The latter is much more interesting from a scientific point of view. In fact, ITS gives the interesting opportunity to optimise the testing strategy when setting new

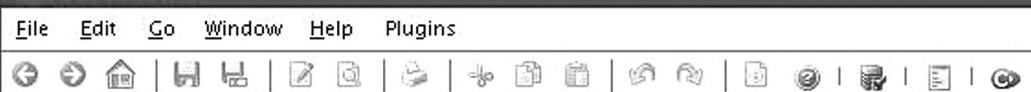

Tast's:

Legal entity

Create and update company forganisation related information

New Update

Substance

Create and update substance related information

New Update

Template

Create and update template related information

New Update

Dossier

Viev dossier data

View Compare egal entity site

Create and update legal entity sites

New Undate

Mixture

Create and update mixture related information

New, Update

\section{Category}

Create and update category related information

New, Update

\section{Inventories}

\section{Inventory}

View EC inventory related information

View, Import
Literature reference

View and exchange literature reference inventony related information

Uiew Exchange

\section{Reference substance}

Create and update reference substance related inform ation

New Update

Tools and administration

Manage users, roles, preferences, etc.

User preferences, Set password, User management, Rale management
Import

Import data from other IUCLID 5 systems

Impart, Bulkimpart

\section{Bulk export}

Export multiple documents

Run

Plugins 
studies in order to maximise the knowledge gained with the minimum requirements in terms of costs and animal sacrifice.

\section{The registrants' reality}

This is the general theory of ambitious REACH principles. Now it is time to reverse the perspective and see the point of view of the registrants. The reality is that there are ten-thousands of importers and manufacturers who must prepare registration dossiers in order to be allowed to go on with their business. This is a very urgent issue, as registration is mandatory for the continued selling and distribution of chemicals. Downstream users are also asked to verify that what they purchase is REACH compliant. At customs, proper REACH documents are required to clear incoming goods. Penalties for non-compliant companies are particularly severe, including jail, for example in case substances of very high concern are used without authorisation (penalties are defined by Member States and they are not homogeneous). This is causing a frantic activity to prepare the dossiers.

This situation is further exacerbated mainly by two factors:

1. The high number of chemicals that need to be registered.

About 140,000 substances have been pre-registered and we estimated (Rovida and Hartung, 2009) that more than 6,000 substances need to be registered by the November 2010 deadline, which is the most demanding in terms of number of tests. In fact, in May 2010 already a voluntary survey in industry documented 4,400 chemicals industry intends to notify by the end of the year, clearly exceeding the original expectation of 2,700 (http://echa.europa.eu_data/list_ registration_2010_en.asp).

2. The severe economic crisis that every business division is facing these days. In consequence, most of the efforts are focused on how to cope with budget loss rather than regulatory compliance.

Being personally involved as a consultant in the preparation of some dossiers, I have had the opportunity to meet many people who are involved in REACH in the different roles described in the regulation, i.e. importers, manufacturers and downstream users. Other actors in the game include contract research organisations (CRO), different types of stakeholders, lawyers and so on. This personal experience drove me to the conclusion that essentially no new (not yet validated) in vitro tests will be performed within the scope of REACH, at least not as an alternative approach to traditional in vivo tests.

The starting point for this conclusion is the simple the perspective of the registrant, who is acting outside the influence of the academic world. There are two main aspects: on one side, there are the personal attitudes of the people involved in the process. The other side is about objective difficulties in submitting results from in vitro tests. Both aspects are equally important and both should be taken into consideration if a more extensive use of in vitro methods and a broader use of ITS are desired.

REACH also considers (Q)SARs to be a useful alternative to animal tests. Even though (Q)SAR shares some of the difficul- ties that in vitro methods have, the methodology is completely different and most of the considerations presented here cannot be extrapolated to (Q)SAR, which are therefore kept out of the scope of this paper.

As food for thought, I will first list some situation/opinions that can capture the general attitude of non-specialists towards the alternative methods. The order of the list is random, not regarding the importance and the frequency these views are expressed. Afterwards, some technical difficulties are presented to show how problematic the application of the Article 1 of this regulation is and why no new in vitro tests will be performed to accomplish the REACH provisions.

\section{Problem type 1: General Clichés}

Even though most of my activity is based in Italy, I have had the opportunity to meet other stakeholders from other European countries (SIEFs are international) and other consultants who are doing the same job in other European countries. Since we are acting in a globalised world, I recorded no major differences between people of different nationalities, e.g. from Italy, Germany or Hungary. The general way of thinking is very similar. There could be a difference depending on the size of the company being represented. Big companies, for example BASF, Henkel and so on can afford highly specialised employees and research laboratories that can scout the latest innovative techniques, being in general highly focused. Small and medium sized enterprises, which are the majority, have more difficulties, as few employees must take care of everything and, in general, regulatory requirements are at the bottom in their list of job priorities.

During my business day, I always try to talk to people about the meaning of alternative methods and about how they can be successfully exploited to define the (eco)toxicological properties of a substance. Hardly ever, but I should actually say never, do I meet people who are familiar with this topic. As a result of this exercise, I have collected some general clichés and list them here. This is just a snapshot to show how people in real life are considering this important opportunity given by REACH. Some comments are spontaneous reactions from people who were surprised when they discovered that I am involved in the subject of alternative methods even though I am a chemist and considered a "serious" expert in the field.

\section{In vitro methods: what are they?}

Most people do not even know they exist. Maybe they have heard something about some movements that want to eliminate laboratory animals, but they relegate them to the sphere of nonglobal stuff and fanaticism. They cannot imagine that in vitro methods may have better scientific validity than in vivo tests.

Animal sacrifice is justified for the health of my children. General opinion is that results from animal tests are always fully reliable and provide precise information about the possible toxicity of a chemical. Most people do not think that animal tests may have a very high rate of false negative and false 
positive results. The thought that animal sacrifice saves lives clears the conscience about any ethical issues related to the use of animals in the labs.

In vivo tests are required. That's it.

Some manufacturers and downstream users are convinced that chemicals are not dangerous. Toxicological assessment is just a burden that is required by regulators to make life more difficult. This category of people cannot be convinced that a more effective strategy can be implemented for a more precise assessment of the chemical. They care only about having all the documents that are required in case of fiscal and other investigations.

One endpoint, one in vivo test.

Two equally important aspects back this attitude: The driving one is the certainty that in vivo tests will be directly accepted by regulators. The other issue can be blamed on mental laziness - just one in vivo test is much easier to organise, to follow and, last but not least, to produce clear results. The box for the corresponding $\mathrm{REACH}$ request is ticked when the report from the laboratory arrives. Nothing else needs to be done. Maybe this approach is more expensive, but it is very much easier. In comparison, ITS must be studied, evaluated, assessed. They require far more management time. There are several reports, maybe from more than one lab and in different formats. Results must be combined and carefully evaluated to reach a conclusion. Exactly for this reason the acquired knowledge about the substance becomes better defined over time, but this is not the main interest of registrant. The truth is that, in the registrant's opinion, besides saving many animals, a proper ITS only has the advantage of being cheaper. This benefit is completely cancelled by the drawbacks of being more difficult and time consuming, and in the end the benefit from cost saving cannot justify the risk of being refused by the regulators.

I have always used that test.

Displacing a procedure that has been in place for decades is very difficult. People are trained one way and they feel much more comfortable to continue the same way. Actually, they have no real reasons to change and the advantage of implementing alternative methods is negligible or even nonexistent for them.

This is my GLP certified procedure.

This is the answer I received from a CRO when I commented on a study protocol that was composed of a first procedure in vivo experiment for a dose range finding study, followed by the usual procedure of testing the substance on three test groups plus control group of animals. Unfortunately, the correspondent OECD guideline clearly states that a limit dose at 1,000 $\mathrm{mg} / \mathrm{kg}$ is accepted when there is no evidence of acute toxicity of the chemical. This specific substance was orally tested for Acute Toxicity at $5,000 \mathrm{mg} / \mathrm{kg}$, with no adverse effects on the animals! I prefer not counting the number of animals that have been used for no purpose and I also hope that the reason for this is ignorance, rather than an inflation of test costs and profits for the laboratory.

\section{Problem type 2: More specific difficulties related to REACH structure}

Apart from personal attitudes of registrants, application of in vitro methodologies within REACH encounters other, more objective difficulties.

\section{Time/Money}

The severe crisis that all industry sectors are facing is a reality. The production outputs of some companies dropped by $80 \%$ in the past year. Nevertheless, registration is still required at the tonnage band that was declared before 2008 (the average quantity of the latest three years) and there is no reduction of test requirements if the actual production level is much lower now. It is easily understandable that many importers/manufacturers put most of their efforts into coping with this painful loss of income instead of caring about how to build up a strategy to use fewer animals for the registration. Unemployment is increasing continually and this is definitely a very serious problem. However, companies must fulfil REACH requirements as a necessary condition for survival. REACH is complex and requires a dedicated person, but there are no resources for new recruitments and some employees are simply moved from other offices in spite of their lack of technical background. Therefore, they can only trust the decision of the SIEF and they cannot comment on the strategies. Quite often, the consulting company in charge of the preparation of a dossier is under much pressure. Increasing the use of alternative methods is advised by the law, but it is not mandatory and nobody wastes time on anything that is not essential. The higher costs of an in vivo test are shared between all the participants and in the end are not that great. In doubt, it is definitely more efficient to spend the time demonstrating that the most expensive tests are not necessary.

\section{Lack of competences}

Few scientists are aware of the benefits provided by a proper ITS strategy. Moreover, most of those are confined to the universities. This demonstrates that alternative approaches are not ready for real-life application. Some laboratories are specialised in in vitro methods. They are usually just starting up their business, also as a consequence of the $7^{\text {th }}$ Amendment of the Cosmetics Directive, which asks for a complete ban of animal use for testing cosmetics and their ingredients (Directive 2003/15/ EC). Major chemical companies are also trying to improve the use of alternative methods for chemical assessment, but their activity is still mainly at the research level.

Again, the lack of competences in this matter is a problem in small and micro enterprises, where few employees must take care of everything, when the complexity of REACH requires full time attention and strong chemical competences.

\section{Negative results from in vitro tests are not accepted by regulators}

Annex XI of REACH accepts the results of a non-validated in vitro test only when they are positive. Negative results must be confirmed in vivo. Most chemicals are not dangerous and the probability of having a negative result is very high. Why should 
an in vitro method then be established? A lot of time and effort is put into the implementation and in the end all is likely to be for nothing. It is true that it is much cheaper than the corresponding in vivo test, but if the in vivo test is still required in the end, any advantage is immediately cancelled.

\section{Positive results from in vitro tests are not accepted by companies}

The lack of knowledge about chemicals has the consequence that most of them are not classified as dangerous and they are not listed in the Annex VI of CLP (classification, labelling and packaging) Regulation (EC 1272/2008). New tests will easily lead to new classification for some chemicals. The consequence for manufacturers and downstream users will be to implement new risk management measures and, even worse, limitations on the applicability of the substance. It is easily understandable that any new positive results will not

\begin{tabular}{|c|c|c|c|}
\hline Query results & Section tree & & \\
\hline \multicolumn{3}{|c|}{ REACH Registration above 1000 tannes } & $\nabla$ \\
\hline \multicolumn{3}{|l|}{$\overrightarrow{\vec{A}}$} & $\nabla$ \\
\hline \multicolumn{4}{|c|}{ O Related Information } \\
\hline \multicolumn{3}{|c|}{1 General Information } & \\
\hline \multicolumn{4}{|c|}{2 Classification and Labelling } \\
\hline \multicolumn{4}{|c|}{ (9. Manufacture, use and exposure } \\
\hline \multicolumn{4}{|c|}{ (t) 4 Physical and chemical properties } \\
\hline \multicolumn{4}{|c|}{ Environmental fate and pathways } \\
\hline \multicolumn{4}{|c|}{$\stackrel{+}{+}=5$ Stability } \\
\hline \multicolumn{4}{|c|}{ (†) 5.2 Biodegradation } \\
\hline \multicolumn{4}{|c|}{5.3 Bioaccumulation } \\
\hline \multicolumn{4}{|c|}{ (†.4 Transport and distribution } \\
\hline \multicolumn{4}{|c|}{ (†) 5.5 Environmental data } \\
\hline \multicolumn{4}{|c|}{5.6 Additional information on environmental fate and behaviour } \\
\hline \multicolumn{4}{|c|}{6 Ecotoxicological Information } \\
\hline \multicolumn{4}{|c|}{ (†) Aquatic toxicity } \\
\hline \multicolumn{4}{|c|}{6.2 Sediment toxicity } \\
\hline \multicolumn{4}{|c|}{ 田..3 Terrestrial toxicity } \\
\hline \multicolumn{4}{|c|}{6.4 Biological effects monitoring } \\
\hline \multicolumn{4}{|c|}{6.5 Biotransformation and kinetics } \\
\hline \multicolumn{4}{|c|}{ 2.6. Additional ecotoxicological information } \\
\hline \multicolumn{4}{|c|}{ ( 7 Toxicological information } \\
\hline \multicolumn{4}{|c|}{ (1.1 Toxicokinetics, metabolism and distribution } \\
\hline \multicolumn{4}{|c|}{ (†) 7.2 Acute Toxicity } \\
\hline \multicolumn{4}{|c|}{7.3 Irritation / corrosion } \\
\hline \multicolumn{4}{|c|}{ (6.4 Sensitisation } \\
\hline \multicolumn{4}{|c|}{ t 7.5 Repeated dose toxicity } \\
\hline \multicolumn{4}{|c|}{$\oplus 7.6$ Genetic toxicity } \\
\hline $7.7 \mathrm{C}$ & rcinogenicity & & \\
\hline$\rightarrow=7.8 \mathrm{~T}$ & xicity to reproduc & & \\
\hline $7.9 \mathrm{si}$ & ecific investigatio & & \\
\hline$\oplus 7.10$ & xposure related o & & \\
\hline 7.11 & oxic effects on liw & & \\
\hline .... 7.12 & dditional toxicolo & & \\
\hline 8 Analyti & al methods & & \\
\hline 11 Guida & ce on safe use & & \\
\hline 12 Litera & dre search & & \\
\hline 13 Asses & ment Reports & & \\
\hline
\end{tabular}

Fig. 2: IUCLID 5.2 section tree related to a substance The sign "+" indicates the presence of another sub-menu. In this picture eco-toxicological information and toxicological information are partially expanded. be readily accepted, and in case a positive result is obtained from an in vitro test, it will be repeated in vivo in the hope of a negative outcome.

\section{In vitro methods + IUCLID 5: mission impossible}

In the end, either because some in vitro data exist or because "scrupulous" submitters have indeed run some in vitro methods despite all the obstacles described, the results must be inserted into IUCLID 5.2. The poor registrant immediately discovers that IUCLID 5.2 was not built to accept in vitro methods. IUCLID 5.2 has a specific section for each single piece of information that is required by REACH (Fig. 2). Each of these sections contains many fields that are typical for that type of study. For example, Table 2 lists the only guidelines that are accepted for the assessment of short-term toxicity to fish. It is true that there is no validated alternative method for this endpoint, but this list does not invite registrants to consider different strategies. All other endpoints are handled exactly the same as shown in Figure 2.

Going on with the compilations, many other details have to be inserted, including information on animal housing, age, feeding procedure and so on. For example, Table 3 lists the number and type of records that are required for inserting data on Repeated Dose Toxicity by oral administration. There are many sections dedicated to in vivo data that remain empty if in vitro methods are used. Most of the required information is in form of numbers or selection from a pre-defined pull-down menu. In vitro data can be inserted only where a box for inserting free text is available. The example of Table 3 is just one, but all other endpoints are very similar.

IUCLID 5.2 compilation is a highly error-prone procedure. That is why ECHA distributed the "Technical Completeness check tool" and the "Business rule verification" to be used before submission. They are both tools embedded in IUCLID 5.2 that check whether the dossier of a substance is ready for submission. If any field of the IUCLID 5.2 file is blank, the check may fail with the consequence that the rejection of the dossier may be highly probable. Since IUCLID 5.2 is designed to accept in vivo data only, most IUCLID 5.2 fields do remain blank when inserting in vitro studies and thus the submission is immediately rejected by the system. There is always the possibility to fill in some explanatory notes about why a field is empty and why the study deviates from accepted OECD in vivo methods, but this is unavoidably more risky for the submitter.

There are now some published OECD guidelines for in vitro tests. However, few of them have been incorporated into IUCLID 5.2, even though the latest update from revision 5.1 was dated February 2010 (ECHA News Alert, 2010), i.e. after many new OECD guidelines for in vitro tests were adopted.

\section{IUCLID 5 Guidance Documents}

ECHA has distributed many guidance documents that are specific for the use of IUCLID 5.2. Two of them are focused on in vitro methods:

- Practical Guide 1: How to report in vitro data (2010)

- Practical Guide 10: How to avoid unnecessary testing on animals (2010) 
The first reinforces the obvious concept that only validated methods are accepted as a key study. Other tests can be used in weight of evidence building. In this guidance there is also a reference to the website of TSAR (Tracking System for Alternative test methods Review, Validation and Approval in the Context of EU Regulations on Chemicals, http://tsar. jrc.ec.europa.eu), where many validated in vitro methods are listed. Afterwards, it explains in practical terms how in vitro data can be used and how to insert them into IUCLID 5.2. Unfortunately, genetic toxicity in vitro is the only dedicated IUCLID 5.2 section. All the others, including skin/eye irritation, still specifically ask for information on animal tests. The guide explains how to use the few boxes into which some free text can be inserted, but it is evident that this is just a quick fix.

The second guideline is on how to avoid unnecessary testing on animals. It mainly describes other opportunities, such as data sharing, read across/grouping and data waiving. Specific topics, such as in vitro methods and (Q)SAR, occupy only a minor part.

\section{Conclusions, with some optimism}

No specific wrapping-up consideration is required to understand that hardly any new in vitro tests will be done for the prepara-

\section{Short term toxicity to fish}

- OECD Guideline 203 (Fish, Acute Toxicity Test)

- OECD Guideline 204 (Fish, Prolonged Toxicity Test: 14-day Study)

- EU Method C.1 (Acute Toxicity for Fish)

- EPA OPP 72-1 (Fish Acute Toxicity Test)

- EPA OPPTS 850.1075 (Freshwater and Saltwater Fish Acute Toxicity Test)

- EPA OPPTS 850.1085 (Fish Acute Toxicity Test mitigated by humic acid)

- EPA OTS 797.1400 (Fish Acute Toxicity Test)

- EPA OTS 797.1460 (Fish Acute Toxicity Test mitigated by humic acid)

- ISO 7346-1 (Determination of the Acute Lethal Toxicity of Substances to a Freshwater Fish [Brachydanio rerio Hamilton-Buchanan (Teleostei, Cyprinidae)] - Part 1: Static method)

- ISO 7346-1 (Determination of the Acute Lethal Toxicity of Substances to a Freshwater Fish [Brachydanio rerio Hamilton-Buchanan (Teleostei, Cyprinidae)] - Part 2: Semi-static method)

- ISO 7346-1 (Determination of the Acute Lethal Toxicity of Substances to a Freshwater Fish [Brachydanio rerio Hamilton-Buchanan (Teleostei, Cyprinidae)] - Part 3: Flow-through method)

- ISO 7346/1-3 (Determination of the Acute Lethal Toxicity of Substances to a Freshwater Fish [Brachydanio rerio Hamilton-Buchanan (Teleostei, Cyprinidae)])

- Other Guideline

Tab. 2: List of guidelines that can be selected for the definition of short-term toxicity to fish

\begin{tabular}{|l|c|l|l|}
\hline IUCLID 5.2 Section & Number of fields & Boxes for free text & Notes \\
\hline Administrative Data and Data Source & 20 & & \\
\hline Materials and Methods & 9 & & \\
\hline Test Material & 5 & 1 & dedicated for in vivo \\
\hline Test Animals & 6 & 7 & dedicated for in vivo \\
\hline Administration, exposure & 14 & 5 & could be used for in vitro \\
\hline Examinations & 5 & 1 & \\
\hline Results and discussion & 30 & 1 & \\
\cline { 2 - 4 } & 1 & 3 & \\
\hline Overall Remarks & 3 & & \\
\hline Applicant Summary and Conclusion & & & \\
\hline
\end{tabular}

Tab. 3: 7.5.1 Repeated Dose Toxicity, oral 
tion of REACH dossiers, at least not in the near future, i.e. for the two deadlines of 2010 (Annex X) and 2013 (Annex IX). Noteworthy, these are the most demanding ones with regard to animal testing. The deadline of June 2018 is for low production volume chemicals, as defined in Annexes VII and VIII of REACH. For that date, the hope is that in vitro methods for the determination of simple endpoints will be available. These could include skin/eye irritation, acute toxicity and skin sensitisation. Unfortunately, a realistic judgement does not allow this list to be longer.

However, there is some spark of optimism also now in terms of the number of animals that will be used.

For the 2010 deadline many costly tests are required by the law, such as carcinogenicity, two-generation reproductive toxicity, 90 day repeated dose toxicity, etc. These are also the most demanding in terms of number of animals. All SIEFs are now struggling to avoid performing those tests, because they are lengthy and expensive. Even if in vitro methods are not applicable, REACH gives other options for waiving (no exposure, low water solubility, ready biodegradability, etc.). Category and read across are also very powerful tools to reduce the number of new in vivo tests done for REACH purposes. They enable extrapolation of test results from one chemical to another, which is regarded as equivalent. The validity of this strategy has to be duly justified, as it is well known that even minor chemical differences may have a strong impact on the biological activity.

Up to now, very few dossiers are proposing one of these large animal tests. It will be up to ECHA whether they will accept this strategy and waive the animal tests. However, this also implies that the information demand remains unfilled.

Apart from these considerations, I personally feel that the main contribution of REACH will be educational. For example, the first step in preparing the dossier is to gather all existing information. This must be inserted into IUCLID 5.2, which forces a specific standardisation. This has a double advantage. Firstly, it is now clear that animal tests performed with different protocols provide different results, even though the chemical and the endpoint studied may be the same. This should help raise awareness about the inherent limitations of in vivo tests. Secondly, as IUCLID 5.2 forces a specific standardisation, new tests will be performed according to the strict rules of the system, providing in the end very high quality in vivo data. Moreover, most of the dossiers will be public, providing a tremendous new database that will be exploited for future in vitro validation. It is well known that lack of data is one of the major bottlenecks for the validation of new in vitro methods (Hartung, 2007; Hoffmann et al., 2008).

In the end, the applicability of in vitro tests will be improved only by making them more appealing. Some proposals are:

1.IUCLID 5.2 should be updated to officially accept data from in vitro tests.

2. Some kind of reward should be given to those who spend time and effort in developing in vitro ITS. This means that the intention of the regulators to foster alternative methods must be transposed into practical advantages for submitters.

3. Something similar should be established for CROs. For example, some sort of funding should be given to laboratories that propose alternative strategies to animal testing.

4.In parallel, a very effective campaign to demonstrate the suffering of animals during the experiments and the uncertainty of results from in vivo tests would be desirable to raise awareness about this problem. The ethical aspect should not be ignored, as it is now, by people who are directly involved in the toxicological assessment of chemicals.

It is a fact that in vitro methods are not ready for regulatory use (Hartung and Daston, 2009). However, more effort should be spent on establishing proper ITS, which can improve the knowledge of toxicological properties and save many animals from cruel tests. In addition to the scientific aspects of this topic, more attention should be given to those actors who need testing for regulatory compliance only. Raising consciousness about advantages of in vitro approaches may bring benefits from both an ethical and scientific point of view.

\section{References}

Directive 2003/15/EC of the European Parliament and of the Council of 27 February 2003 amending Council Directive $76 / 768 / \mathrm{EEC}$ on the approximation of the laws of the Member States relating to cosmetic products Official Journal of the European Union L 66, 26-35.

European Risk Observatory Report (2009). Expert forecast on emerging chemical risks related to occupational safety and health. http://osha.europa.eu/en/publications/reports/ TE3008390ENC_chemical_risks (accessed 30 June 2010).

ECHA News Alert (2010). IUCLID 5.2 is now available. ECHA/NA/10/04

Hartung, T. and Daston G. (2009). Are in vitro tests suitable for Regulatory use? Toxicological Science 111(2), 233-237

Hartung, T and Rovida, C. (2009). Chemical regulators have overreached. Nature 460, 1080-1081.

Hartung, T. (2007). Food for thought ... on validation. ALTEX 24, 67-72.

Hoffmann, S., Edler, L., Gardner, I. et al. (2008). Points of reference in validation - the report and recommendations of ECVAM Workshop. ATLA 36, 343-352.

Pedersen, F., de Bruijn, J., Munn, S. and van Leeuwen, K. (2003). Assessment of additional testing needs under REACH - effects of (Q)SARs, risk based testing and voluntary industry initiatives. JRC Report EUR 20863. http://ecb. jrc.ec.europa.eu/documents/REACH/PUBLICATIONS/ REACH_testing_needs_final.pdf (accessed on 26 July 2010)

Practical Guide 1: How to report in vitro data (2010). ECHA10-B-04-EN

Practical Guide 10: How to avoid unnecessary testing on animals (2010). ECHA-10-B-17-EN

REACH (2006). Regulation (EC) No 1907/2006 of the Euro- 
pean Parliament and of the Council of 18 December 2006 concerning the Registration, Evaluation, Authorisation and Restriction of Chemicals (REACH), establishing a European Chemicals Agency, amending Directive 1999/45/EC and repealing Council Regulation (EEC) No 793/93 and Commission Regulation (EC) No $1488 / 94$ as well as Council Directive 76/769/EEC and Commission Directives 91/155/ EEC, 93/67/EEC, 93/105/EC and 2000/21/EC., 1-849.

Regulation 134 (2009). Commission Regulation (EC) No 134/2009 of 16 February 2009 amending Regulation (EC) No 1907/2006 of the European Parliament and of the Council on the Registration, Evaluation, Authorisation and Restriction of Chemicals (REACH) as regards Annex XI. Official Journal of the European Union L 46, 3-5.

Regulation (EC) No 1272/2008 of the European Parliament and of the Council of 16 December 2008 on classification, labelling and packaging of substances and mixtures, amending and repealing Directives 67/548/EEC and 1999/45/EC, and amending Regulation (EC) No 1907/2006

Rovida, C. and Hartung, T. (2009). Re-evaluation of animal numbers and costs for in vivo tests to accomplish REACH legislation requirements for chemicals. ALTEX 26, 187-202.

van der Jagt, K., Munn, S., Tørsløv, J. and de Bruijn, J. (2004). Alternative approaches can reduce the use of test animals under reach. Addendum to the report: Assessment of addi- tional testing needs under REACH Effects of (Q)SARS, risk based testing and voluntary industry initiatives. JRC Report EUR $21405 E N$, http://ecb.jrc.ec.europa.eu/documents/ REACH/PUBLICATIONS/Reducing_the_use_of_test_animals_under_REACH_IHCP_report.pdf (accessed 26 July 2010).

White Paper (2001). Strategy for a future Chemicals Policy. COM 88 final, Brussels, 27.2.2001

\section{Acknowledgments}

I would like to thank Prof. Dr. Thomas Hartung for critically reading this manuscript. The review from CAAT staff and the input for the figures by Alessandro Buccheri are gratefully appreciated.

\section{Correspondence to}

Costanza Rovida

CAAT-EU

University of Konstanz

78457 Konstanz

Germany

Tel.: +497531882233

e-mail: costanza.rovida@chimici.it 